\title{
Network Reconfiguration for Reliability Worth Enhancement in Distribution System by Simulated Annealing
}

\author{
Somporn Sirisumrannukul \\ Department of Electrical Engineering, Faculty of Engineering \\ King Mongkut's University of Technology North Bangkok \\ Thailand
}

\section{Introduction}

The distribution system is an important part that provides the final links between the utility and the customers. Most distribution systems in practice have a single-circuit main feeder and are radially configured. The radial distribution system is widely used because of its simple design, generally low cost and supportive protection scheme. This configuration suggests from a reliability point of view that all components between a load point and the supply point must work and therefore poor reliability can be expected as the failure of any single component causes the load point to be disconnected.

The reliability in a distribution system can be improved by network reconfiguration, which is accomplished by closing normally-open switches and opening normally closed switches (Brown, 2001). These switches play an important role in reducing interruption durations in the event of a system failure. Two types of switches are normally installed along the main feeders and laterals: sectionalizing switch (normally closed switch) and tie switch (normally open switch). The former is a device that isolates a faulted part from the system so that the healthy part can still be electrically supplied. The latter is a device that recovers loads that has been disconnected by transferring some of the loads to other supporting distribution feeders without violating operation and engineering constraints (Chowdhury, 2001). Apparently, different network configurations due to an alteration of the switch statuses provide different services to the customers.

A great deal of work has been done on network reconfiguration (also known as feeder reconfiguration) in distribution systems mainly in the context of active power loss reduction because the cost of MW loss occupies considerable amount of operating cost in the system and therefore small amount achieved from loss reduction is still attractive for electric power utilities. A number of methods have been proposed to solve feeder reconfiguration for loss minimization, such as integer programming (Sarma \& Prakasa Rao, 1995) and artificial neural network (Kashem et al., 1998) and simulated annealing (Chang \& Kuo, 1994). The reconfiguration problem in this case are normally subject to power balance equations, bus voltage upper and lower limits, line carrying capability of the feeders and radial topology of the network. Other constraints may be taken into account, for example, load balancing 
(Zhou et al., 1997), introduction of distributed generation (Nathachot \& Sirisumrannukul, 2009) and capacitor placement (Su \& Lee, 2001).

Very little has been paid attention to reliability improvement by feeder reconfiguration. Tsai, L. H. presented a model for improving the reliability of electric distribution systems through network reconfiguration. Two main reliability indices are targeted to be minimized: system average interruption frequency (SAIFI) and the system average interruption duration (SAIDI). The mathematical formulations for calculating the change of SAIDI and SAIFI as a result of reconfiguration were developed to identify beneficial load transfers. However, his method did not take into account reliability worth, which can be described in terms of customer interruption costs.

Ye Bin et. al proposed network reconfiguration to increase reliability worth by an improved genetic algorithm. The mathematical model is formuated in which its objective function is to minimize customer interruption costs. The procedure was illustrated by the distribution system connected at bus 2 of the 6-bus Roy Billitton Test System (RBTS). It is shown from their studies that their developed methodology permits flexible use of sectionalizing and tie switches without introducing additional costs while being able to achieve large possible economic benefit.

The emphasis of this chapter is given to reliability worth enhancement in distribution systems, where a good network topology can significantly improve load point reliability. However, a good connection is not straightforward to be identified as the large number of on/off switch statuses needs to be determined. In addition, some configurations are not allowed because they lead either to an isolated system or to a non-radial system. Theoretically, the complete enumeration can be used to arrive at an optimal solution while satisfying the constraints. Nevertheless, such an exhaustive technique would be practically impossible. Alternatively, simulating annealing (SA), which is one of powerful searching techniques for combinatorial optimization problems, can be served as a tool for on/off decision making of the switches in the system. This technique imitates the behavior of a set of atoms in the annealing of metals. The cooling procedure goes gradually from a high temperature to a freezing point, where the energy of the system has acquired the globally minimal value. This physical annealing process is analogous to the determination of nearglobal or global optimum solutions for optimization problems.

A SA algorithm for network reconfiguration is developed to identify the most appropriate topology that gives the lowest customer interruption cost. Customer interruption costs are calculated from load point reliability indices and their customer damage functions. The developed algorithm is tested with a distribution system connected at bus 2 of the RBTS, which consists of 4 feeders and 22 load points, and a 69-bus distribution system, which consists of 7 feeders and 69 load points.

\section{Simulated Annealing}

Simulated annealing is physically referred to the process of heating up a solid with a high temperature. The molten solid is then gradually cooled until it is solidified at a low temperature. At each step of the cooling, the temperature is kept constant for a period of time in order to allow the solid to reach thermal equilibrium where the solid could have many configurations. 
This physical annealing process is analogous to the determination of near-global or global optimum solutions for optimization problems. The underlying idea is to begin with a current atomic configuration. This configuration is equivalent to the current solution of an optimization problem. The energy of the atoms is analogous to the cost of the objective function and the final ground state corresponds to the global minimum of the cost function (Aarts, 2001) (Winton, 2003). The analogy between physical system and optimization problem is shown in Table 1.

\begin{tabular}{|c|c|}
\hline Physical system & Optimization problem \\
\hline State & Feasible solution \\
\hline Energy & Cost \\
\hline Ground state & Optimal solution \\
\hline Rapid quenching & Local search \\
\hline Careful annealing & Simulated annealing \\
\hline
\end{tabular}

Table 1. Analogy between simulated annealing and optimization

On the basis of the above analogy, the main idea of the SA algorithm is to initialize randomly a feasible solution, $x_{0}$. The energy $E\left(x_{0}\right)$, which is equivalent to objective function, of the initial solution will be evaluated. A new candidate solution is randomly generated in the neighborhood of the current one. The move to the new candidate feasible solution is accepted if it is superior in the objective value to the current one (i.e., a reduction in the objective function for a minimization problem). Nevertheless, an inferior candidate solution has a chance of acceptance with a probability, $p$, given by the Boltzmann distribution.

$$
p=\exp (-\Delta E / k T)
$$

where $\Delta E=$ change in objective value

$k=$ Boltzmann's constant

$T=$ current temperature

A uniformly distributed random number, $r$, is drawn in the range $[0,1]$. The move to the inferior solution is accepted if the random number is less than $p$; otherwise the move is discarded. Such an acceptance avoids getting trapped on a local optimal solution and therefore expands the search space. The last accepted solution for each temperature $T_{i}$ forms the initial solution of the next stage. The temperature is gradually lowered (e.g., $T_{i+1}=\alpha T_{i}$, where $\alpha$ is a constant between 0 and 1) and the algorithm proceeds until a stopping criterion (say, temperature is less than a minimum specified temperature $T_{\min }$ ) or another preset stopping criteria are satisfied. A flowchart for simulated annealing algorithm is shown in Fig. 1 (Weck, 2004).

For a constrained optimization problem, its solutions can be obtained from penalty function methods. The main idea behind these methods is to convert a constrained optimization problem into an unconstrained one, whose objective function is formed by attaching the constraints to the original objective function. The unconstrained problem with the 
augmented objective function can be solved by SA. With a penalty function method, infeasible solutions will be penalized by a penalty factor multiplied by their degree of violation.

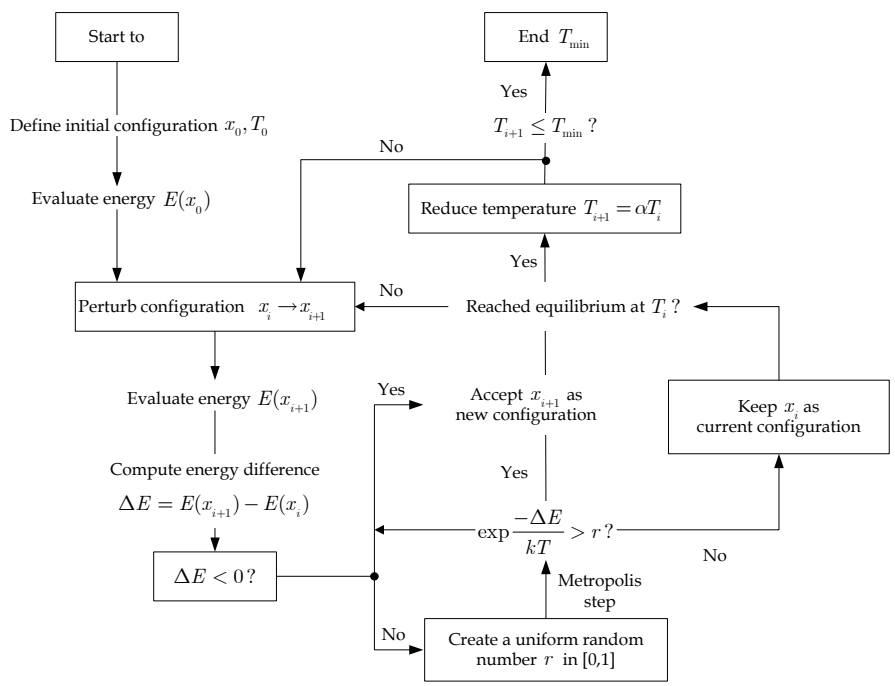

Fig. 1. Simulated annealing algorithm

\section{Distribution Reliability Indices}

A distribution circuit normally uses primary or main feeders and lateral distributions. A primary feeder originates from a substation and passes through major load centers. The lateral distributors connect the individual load points to the main feeder with distribution transformers at their ends. Many distribution systems used in practice have a single-circuit main feeder and defined as radial distribution system. A radial distribution system consists of series components (e.g., lines, cables, transformers) to load points. This configuration requires that all components between a load point and the supply point operate; and hence the distribution system is more susceptible to outage in a single event. There are two types of reliability indices evaluated in the distribution system: load point reliability indices and system reliability indices (Billinton \& Allan,1996).

\subsection{Load Point Reliability Indices}

The basic distribution system reliability indices of a load point $p$ are average failure rate $\lambda_{p}$, average outage duration $r_{p}$ and annual outage time $U_{p}$. These three basic indices are calculated using the priciple of series systems and given by

$$
\lambda_{p}=\sum_{i=1}^{n} \lambda_{i}
$$




$$
\begin{gathered}
U_{p}=\sum_{i=1}^{n} \lambda_{i} r_{i} \\
r_{p}=\frac{U_{p}}{\lambda_{p}}=\frac{\sum_{i=1}^{n} \lambda_{i} r_{i}}{\sum_{i=1}^{n} \lambda_{i}}
\end{gathered}
$$

where $n=$ number of outage events affecting load point $p$

$\lambda_{i}=$ failure rate of component $i$ (failure/yr or, in short, $\mathrm{f} / \mathrm{yr}$ )

$r_{i} \quad=$ repair time of component $i(\mathrm{hr})$

\subsection{Customer Oriented Reliability Indices}

With the three basic load point indices and energy consumption at load points, system average interruption frequency index (SAIFI), system average interruption duration index (SAIDI), average service availability (ASAI), average service unavailability (ASUI), energy not supplied (ENS) and average energy not supplied (AENS) can be calculated. These six customer oriented reliability indices are obtained from

$$
\begin{aligned}
& \text { SAIFI }=\frac{\sum_{j=1}^{n l} \lambda_{j} N_{j}}{\sum_{j=1}^{n l} N_{j}} \quad \text { (interruptions/customer) } \\
& \text { SAIDI }=\frac{\sum_{j=1}^{n l} U_{j} N_{j}}{\sum_{j=1}^{n l} N_{j}} \quad \text { (hours/customer) } \\
& \sum_{j=1}^{n l} N_{j} \times 8760-\sum_{j=1}^{n l} U_{j} N_{j} \sum_{j=1}^{n l} N_{j} \times 8760 \\
& \mathrm{ASUI}=1-\mathrm{ASAI} \\
& \mathrm{ENS}=\sum_{j=1}^{n l} L_{a(j)} U_{j} \\
& \mathrm{AENS}=\frac{E N S}{\sum_{j=1}^{n l} N_{j}} \quad(\mathrm{kWh} / \mathrm{customer}) \\
&(\mathrm{kWh})
\end{aligned}
$$




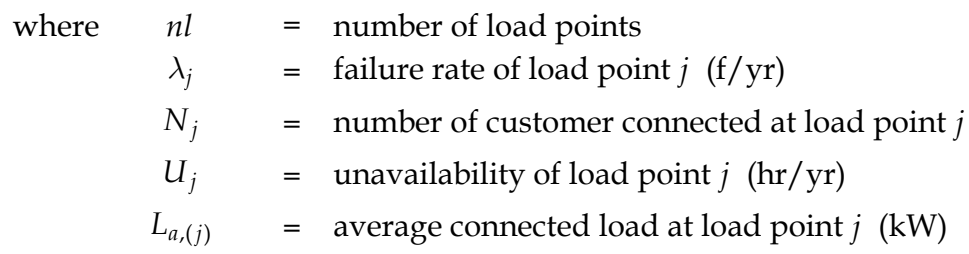

\section{Quantification of Reliability Worth}

Reliability worth can be quantified in forms of customer interruption costs. Customer interruption costs provide an indirect measure of monetary losses associated with a power failure and are served as input data for cost implications and worth assessments of system planning and operational decisions. The calculation of customer interruption costs requires distribution reliability indices of the load points and customer interruption cost data.

Customer interruption cost data, compiled from customer surveys, are used to develop a sector customer damage function (SCDF). The SCDF is a function of customer class and outage duration, which can be used to estimate monetary loss incurred by customers due to power failure. Table 2 shows the SCDF for seven sectors of customers for five discrete outage durations (Goel et al., 1991). The outage cost data in the table is plotted as shown in Fig. 2. Using interpolation or extrapolation techniques, the cost of interruption for any other duration is determined by interpolation.

\begin{tabular}{|l|l|l|l|l|l|}
\hline \multirow{2}{*}{ User sector } & Interruption duration (minutes) \\
\cline { 2 - 6 } & $\mathbf{1}$ & $\mathbf{2 0}$ & $\mathbf{6 0}$ & $\mathbf{2 4 0}$ & $\mathbf{4 8 0}$ \\
\hline Large users & 1.005 & 1.508 & 2.225 & 3.968 & 8.24 \\
\hline Industrial & 1.625 & 3.868 & 9.085 & 25.16 & 55.81 \\
\hline Commercial & 0.381 & 2.969 & 8.552 & 31.32 & 83.01 \\
\hline Agricultural & 0.06 & 0.343 & 0.649 & 2.064 & 4.12 \\
\hline Residential & 0.001 & 0.093 & 0.482 & 4.914 & 15.69 \\
\hline Goverment and institute & 0.044 & 0.369 & 1.492 & 6.558 & 26.04 \\
\hline Office and building & 4.778 & 9.878 & 21.06 & 68.83 & 119.2 \\
\hline
\end{tabular}

Table 2. Sector customer damage cost $(\$ / \mathrm{kW})$

The contingency enumeration method (Geol \& Billinton, 1994) estimates the expected interruption cost (ECOST). This method considers each outage event in association with the interruption cost data of the customers. The system model consists of relevant reliability parameters of all components such as the main and lateral feeders, factors such as the inclusion or not of disconnects on the main feeders, fuses in the lateral sections, alternate back-fed supply, replacing a failed low voltage transformer or using a spare instead of repairing it, etc. The ECOST of load point $p$ is evaluated by 


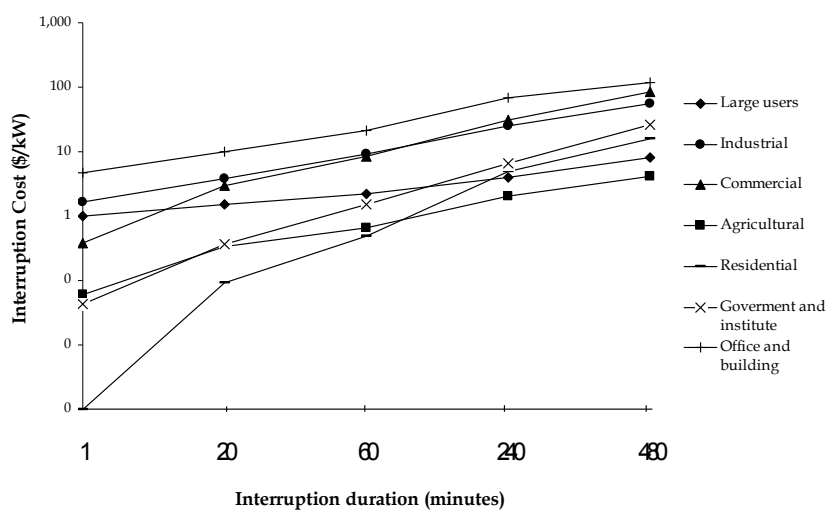

Fig. 2. Section customer damage function

$$
\operatorname{ECOST}_{p}=\sum_{k=1}^{n c} C_{k, p}\left(r_{k}\right) L_{a v, p} \lambda_{k}
$$

where $E C O S T_{p}=$ expected interruption cost of load point $p(\$)$

$$
\begin{aligned}
L_{a v, p} & =\text { average connected load at load point } p(\mathrm{~kW}) \\
C_{k, p}\left(r_{k}\right)= & \text { cost for contingency } k \text { of load point } p \text { with an outage duration } \\
& \text { of } r_{k}(\$ / \mathrm{kW}) \\
r_{k} & =\text { average outage time of contingency } k \\
\lambda_{k} & =\text { failure rate of contingency } k(\mathrm{f} / \mathrm{yr}) \\
n c & =\text { number of contingencies that isolate load point } p
\end{aligned}
$$

\section{Optimization of Network Reconfiguration}

The objective function is to minimize the total interruption cost given in (11), subject to the following two constraints: the system is still radially operated and all the load points are still electrically supplied.

$$
\operatorname{minimize} \sum_{j=1}^{n l} E C O S T_{j}
$$

The optimal or near optimal solution of (12) can be found by the following simulated annealing algorithm.

Step 1: Read the feeder length, statistical operating data and customer damage function of the distribution network.

Step 2: Specify sufficiently high temperature, cooling schedule, initial network configuration, minimum temperature and penalty factor and set $i=0$. 
Step 3: Initialize feasible statuses of the switches $x_{i}$ and calculate the associated interruption cost $\operatorname{ECOST}\left(x_{i}\right)$. Feasible statuses can be found from an existing configuration.

Step 4: Generate new statuses of the switches $x_{i+1}$. If the new configuration satisfies the two system constraints, a new interruption cost $\operatorname{ECOST}\left(x_{i+1}\right)$ is calculated, or a penalty factor is applied to the objective function.

Step 5: Perform an acceptance test for the new solution in step 4 . If $\Delta E C O S T=E \operatorname{COST}\left(x_{i+1}\right)-E \operatorname{COST}\left(x_{i}\right)<0$, the new interruption cost is accepted as it is superior to the previous one, otherwise go to step 5 .

Step 6: Generate a uniform random number in the range [0, 1] and calculate the probability of acceptance $p=\exp (-\Delta E C O S T / k T)$. If $r<p$, the interruption cost obtained in step 6 is accepted and proceed to step 7; if not, return to step 3.

Step 7: Decrease the temperature in the next iteration by setting $T_{i+1}=\alpha T_{i}$, where $0<\alpha<1$.

Step 8: Terminate the calculation process if $T \leq T_{\min }$ where $T_{\min }$ is minimum specified temperature; otherwise $k=k+1$ and repeat steps 2-7.

\section{Case Study}

The developed methodology is tested with bus 2 of the RBTS (Allan et al., 1991) and a 69bus distribution system (Chiang \& Jean-Jameau, 1990).

\subsection{RBTS}

The $33 \mathrm{kV}$ distribution system at bus 2 of the RBTS is employed in this case study, as shown in Fig. 3. The reliability data of the components are provided in Table A. 1 of Appendix. Feeder and transfomer are listed in Tables A.2 and A.3 respectively. The average and maximum loads of this system are 12.291 MW and 20.00 MW (i.e., the system load factor is 0.61455). The feeders are operated as radial feeders but connected as a mesh through normally open sectionalizing points in the event of system failure. The system has sectionalizing switches in the main feeders, fuses in each lateral branch and an alternative supply at the end of each feeder. Note that there is only one sectionalizing switch installed at one side of each lateral branch tapped from the main feeder. The recovery of a failed transformer is replaced by a spare one. The distribution system has 2 tie switches, 14 sectionalizing switches, 22 load points, 22 transformers and 6 circuit breakers.

The customer and loading data are provided in Table A.4. The SCDF for this system is shown in Fig. 1. These studies consider the $11 \mathrm{kV}$ feeders only and ignore any failures in the $33 \mathrm{kV}$ system, the $33 / 11 \mathrm{kV}$ substation and the $11 \mathrm{kV}$ breakers. It is assumed that the $11 \mathrm{kV}$ source breaker operates successfully when required, sectionalizing switches are opened whenever possible to isolate a fault, and the supply restored to as many load points as possible using appropriate disconnects and the alternative supply if available (Allan et al., 1991). Feeder and transformer section numbers are circled in Fig. 3. 


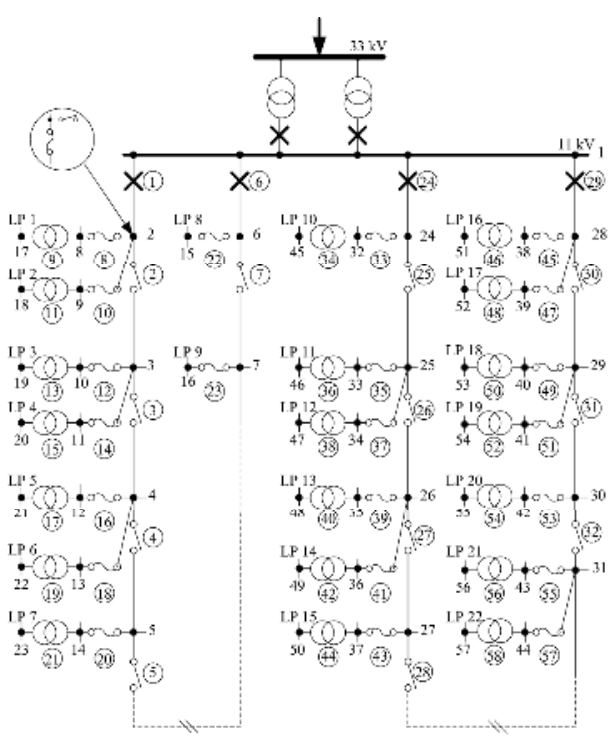

a) before reconfiguration

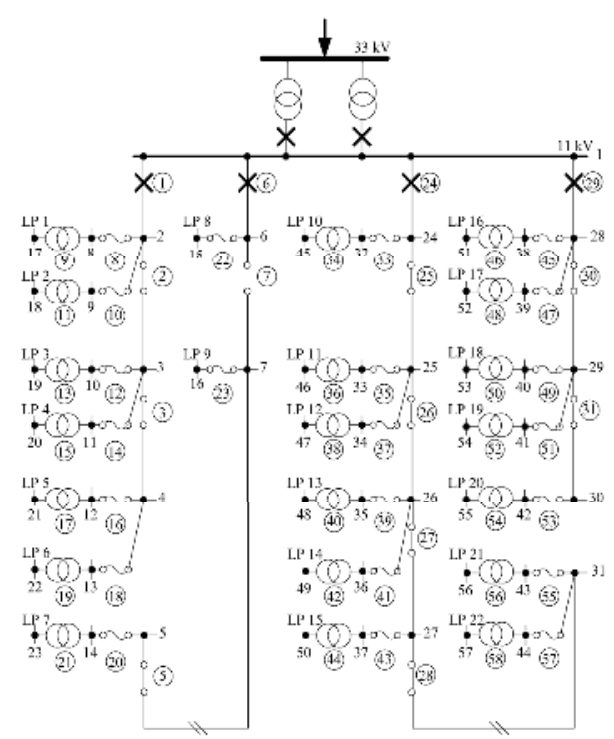

b) after reconfiguration

Fig. 3. Distribution system of bus 2 of RBTS

A SA-based computer program for distribution network reconfiguration was developed on and tested on Intel Processor Core (TM) Duo CPU 2.4 GHz, RAM 3 GB. The maximum number of temperatures is specified at 3,000 with a step size $(\alpha)$ of 0.00025 for temperature scaling. The annealing process will be terminated if the maximum number of temperatures has been reached.

The algorithm starts with tie switches No. 5 and No. 28 left open while all sectionalizing switches are closed (designated as pattern 1). This initial configuration gives load point reliability indices listed in Table 3 and a system interruption cost of $\$ 199,680$ as shown in Table 4. The optimal solution obtained from the simulated annealing algorithm is to open sectionalizing switches No. 4 and No. 32 and to close tie switches No. 5 and No. 28 (pattern 2 ), giving an ECOST of $\$ 197,360$. Such switch statuses satisfy the two system constraints and make an annual saving of $\$ 2,320$. For a practical distribution system with thousands of feeders, the annual saving will be much more significant. If the two tie switches remains closed, Table 5 shows moves from the optimal solution to two other neighborhood solutions (patterns 3 and 4 ) of sectionalizing switches, which produce higher ECOSTs compared with that of the optimal one. The convergence report of the simulated annealing algorithm is shown in Fig. 4, from which the solution remains unchanged after 1,700 drops in the temperature. This system takes about 4 seconds to converge.

It is very interesting to note that if we consider minimizing the system ENS, instead of the system ECOST, the result is shown in Table 6. It can be seen that setting the system ENS as the objective function yields different switch statuses because the SCDF fails to be realized in the later case. In other words, $1 \mathrm{MWh}$ for energy not served for one load point does not produce the same effect as the others. In short, as far as monetary matter is of priority, the ECOST minimization would be more appropriate. In this case, not only is the system ECOST 
reduced, but also the system reliability indices like SAIFI, SAIDI, ASAI and ENS are seen improved, signifying the benefit of network or feeder reconfiguration.

\begin{tabular}{|c|c|c|c|c|c|c|c|}
\hline $\begin{array}{c}\text { Load } \\
\text { Point }\end{array}$ & $\begin{array}{c}\lambda \\
(\mathbf{f} / \mathbf{y r})\end{array}$ & $\begin{array}{c}r \\
(\mathbf{h r})\end{array}$ & $\begin{array}{c}U \\
\mathbf{( h r} / \mathbf{y r})\end{array}$ & $\begin{array}{c}\text { Load } \\
\text { Point }\end{array}$ & $\begin{array}{c}\lambda \\
\mathbf{f} / \mathbf{y r})\end{array}$ & $\begin{array}{c}r \\
\mathbf{( h r})\end{array}$ & $\begin{array}{c}U \\
\mathbf{( h r} / \mathbf{y r})\end{array}$ \\
\hline 1 & 0.240 & 14.90 & 3.58 & 12 & 0.256 & 14.29 & 3.66 \\
\hline 2 & 0.253 & 14.40 & 3.64 & 13 & 0.253 & 14.19 & 3.59 \\
\hline 3 & 0.253 & 14.40 & 3.64 & 14 & 0.256 & 14.08 & 3.61 \\
\hline 4 & 0.240 & 14.90 & 3.58 & 15 & 0.243 & 14.73 & 3.58 \\
\hline 5 & 0.253 & 14.40 & 3.64 & 16 & 0.253 & 14.40 & 3.64 \\
\hline 6 & 0.250 & 14.51 & 3.63 & 17 & 0.243 & 14.78 & 3.59 \\
\hline 7 & 0.253 & 14.24 & 3.60 & 18 & 0.243 & 14.73 & 3.58 \\
\hline 8 & 0.140 & 3.89 & 0.54 & 19 & 0.256 & 14.24 & 3.65 \\
\hline 9 & 0.140 & 3.60 & 0.50 & 20 & 0.256 & 14.24 & 3.65 \\
\hline 10 & 0.243 & 14.73 & 3.58 & 21 & 0.253 & 14.19 & 3.59 \\
\hline 11 & 0.253 & 14.40 & 3.64 & 22 & 0.256 & 14.08 & 3.61 \\
\hline
\end{tabular}

Table 3. Initial load point relaibility indices of bus 2 of RBTS

\begin{tabular}{|l|c|c|}
\hline \multicolumn{1}{|c|}{ Reliability indices } & Before reconfiguration & After reconfiguration \\
\hline SAIFI (failure/customer/yr) & 0.248 & 0.222 \\
\hline SAIDI (hr/customer/yr) & 3.612 & 3.584 \\
\hline ASUI & 0.00041 & 0.00040 \\
\hline ASAI & 0.99959 & 0.99960 \\
\hline ENS (MWh/yr) & 37.745 & 37.254 \\
\hline ECOST (k\$/yr) & 199.68 & 197.35 \\
\hline AENS (MWh/customer/yr) & 19.78 & 19.52 \\
\hline Sectionalizing switches to be opened & - & 4,32 \\
\hline Tie switches to be closed & - & 5,28 \\
\hline
\end{tabular}

Table 4. Simulation results before and after reconfiguration for RBTS

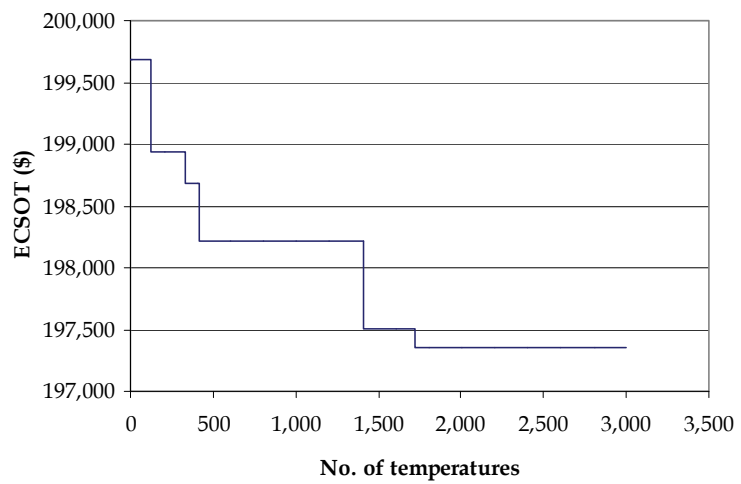

Fig. 4. Convergence report for customer interruption cost of RBTS 


\begin{tabular}{|c|c|c|}
\hline Pattern & Sectionalizing switch No. & ECOST (\$) \\
\hline 1 & - & 199,677 \\
\hline 2 & 4,32 & 197,358 \\
\hline 3 & 3,32 & 197,668 \\
\hline 4 & 4,27 & 197,511 \\
\hline
\end{tabular}

Table 5. Simulation results for ECOST minimization

\begin{tabular}{|c|c|c|}
\hline Pattern & Sectionalizing switch No. & ENS (MWh) \\
\hline 1 & - & 37.7457 \\
\hline 2 & 4,32 & 37.2546 \\
\hline 3 & 3,32 & 37.1023 \\
\hline 4 & 4,27 & 37.2883 \\
\hline
\end{tabular}

Table 6. Simulation results for ENS minimization

\subsection{9-Bus System}

The test system is a $12.66 \mathrm{kV}$ radial distribution system with 69 buses, 7 laterals and 5 tielines (looping branches). The single line diagram of this system is shown in Fig. 5. Each branch in the system has a sectionalizing switch for reconfiguration purpose. There are 69 load points, 69 fuses, 69 transformers and 1 circuit breaker at the substation. As in the case of RBTS, the circuit breaker, the sectionalizing switches, and the fuses are all considered fully reliable and only one sectionalizing switch is installed on one side of each lateral. The statistical data of system equipment are given in Table A.5. The feeder and transformer data are provided in Tables A.6 and A.7. All the feeders and laterals are considered as overhead lines. The customer damage function is shown in Table 7, the data of which is plotted as shown in Fig. 6. The system has an average demand of $52.613 \mathrm{MW}$, a load factor of 0.63 , and 6,120 customers. The maximum number of temperature is set at 100,000.

Figures 7, 8 and 9 show, respectively, three basic load point reliability indices for this system; namely, average failure rate $(\lambda)$, average outage duration $(r)$ and annual outage time $(U)$. Compared with the RBTS, this system has higher failure rates and hence annual outage times mainly because there are more components in series that affect the load points. The initial configuration states that the tie switches located on branch No. 208-212 are open while all the sectionalizing switches are closed. With this configuration, the initial ECOST is $\$ 159,672$. The optimal solution for this system, as shown in Fig. 10, indicates that tie switch No. 209, 210, 212 remains open and the statuses of tie switch No. 208 and 211 are changed from 'open' to 'closed', giving a ECOST of $\$ 27,799$. Only two sectionalizing switches are required to be opened: switch No. 43 and No. 59. This system sees a reduction in ECOST of $\$ 27,799$, accounting for $17.41 \%$. The computation time is 80 seconds. A summary of simulation results before and after reconfiguration is given in Table 8 . 


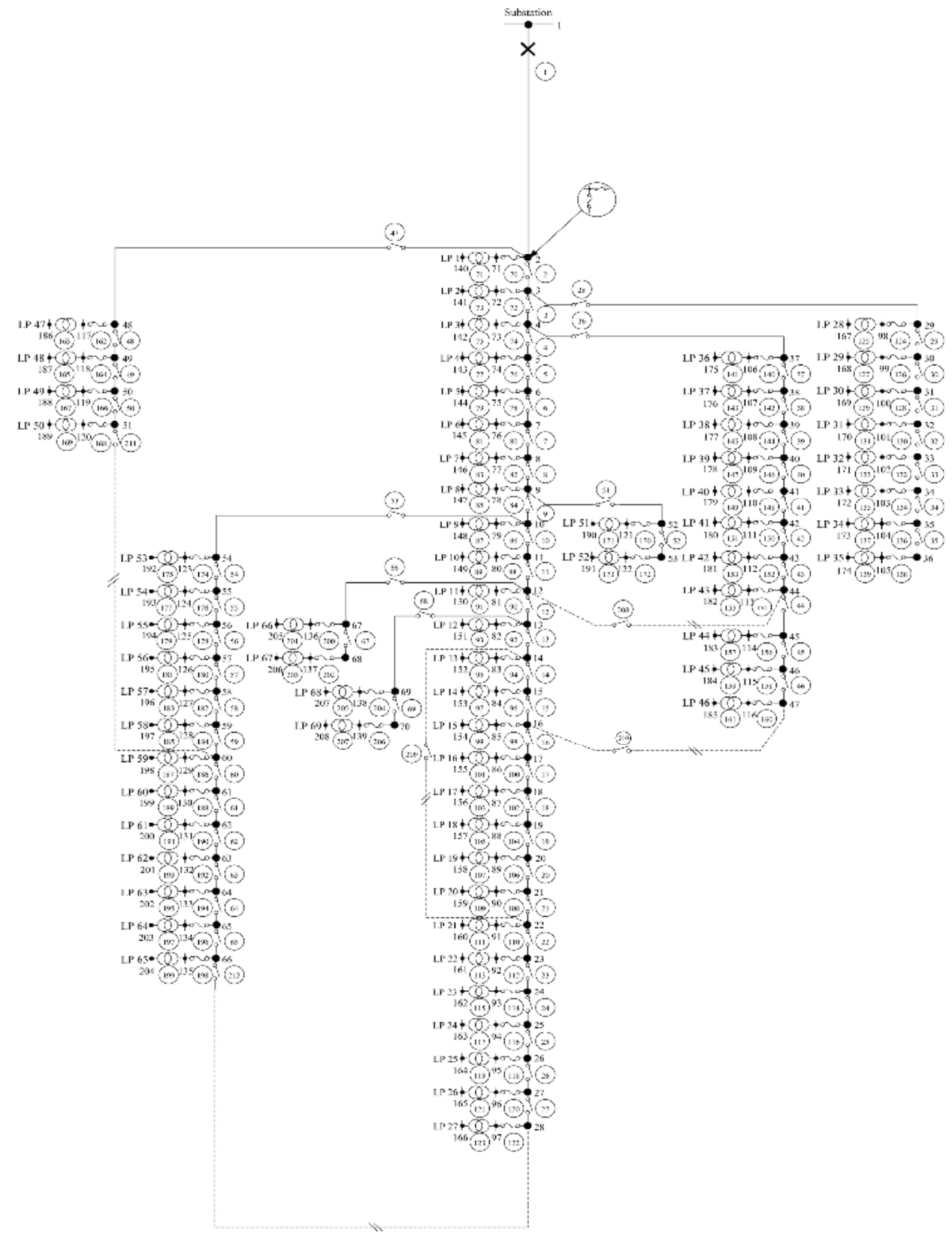

Fig. 5. 69-bus system before reconfiguration 


\begin{tabular}{|l|l|l|l|l|l|}
\hline \multirow{2}{*}{ User sector } & \multicolumn{5}{l}{ Interruption duration (minutes) } \\
\cline { 2 - 7 } & $\mathbf{1}$ & $\mathbf{2 0}$ & $\mathbf{6 0}$ & $\mathbf{2 4 0}$ & $\mathbf{4 8 0}$ \\
\hline Commercial & 0.130 & 0.143 & 0.148 & 0.173 & 0.381 \\
\hline Educational & 0.018 & 0.025 & 0.027 & 0.044 & 0.054 \\
\hline Office and building & 0.248 & 0.287 & 0.351 & 0.494 & 4.778 \\
\hline Residential & 0.001 & 0.005 & 0.008 & 0.020 & 0.033 \\
\hline Small industrial & 0.105 & 0.116 & 0.151 & 0.193 & 1.626 \\
\hline Large industrial & 1.005 & 1.508 & 2.225 & 3.968 & 8.240 \\
\hline
\end{tabular}

Table 7. Sector customer damage cost for 69 -bus system $(\$ / \mathrm{kW})$

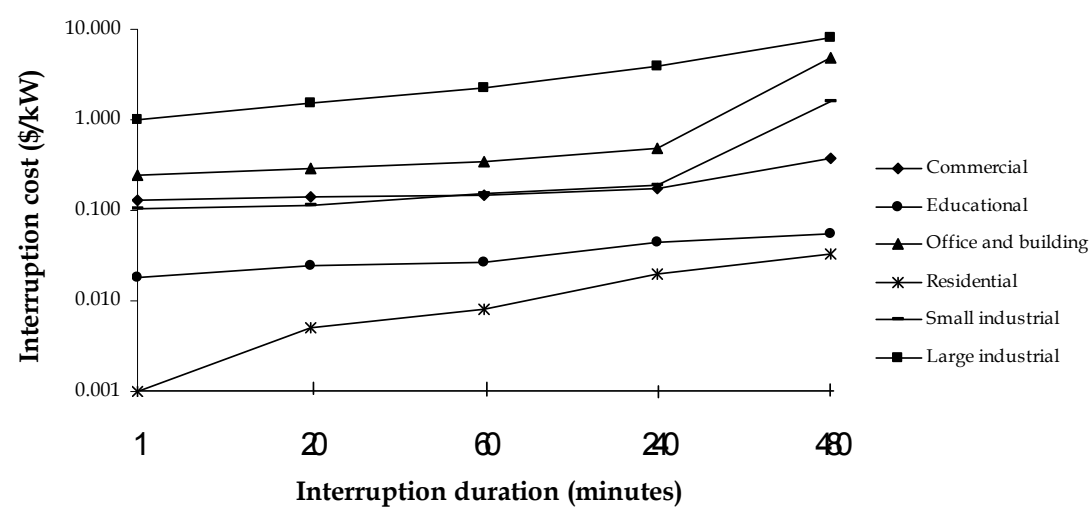

Fig. 6. Sector customer damage cost of 69-bus system

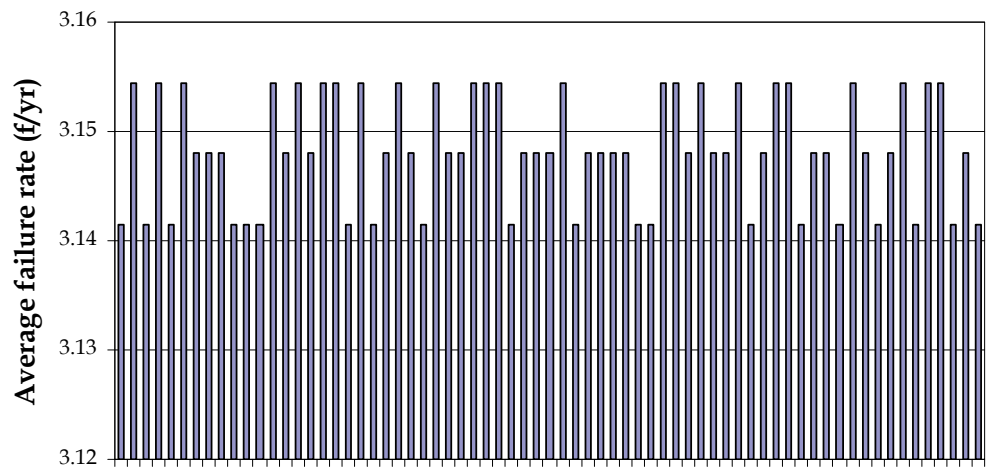

$\begin{array}{lllllllllllllllllllllll}1 & 4 & 7 & 10 & 13 & 16 & 19 & 22 & 25 & 28 & 31 & 34 & 37 & 40 & 43 & 46 & 49 & 52 & 55 & 58 & 61 & 64 & 67\end{array}$

\section{Load point}

Fig. 7. Average failure rate of load points of 69-bus system 


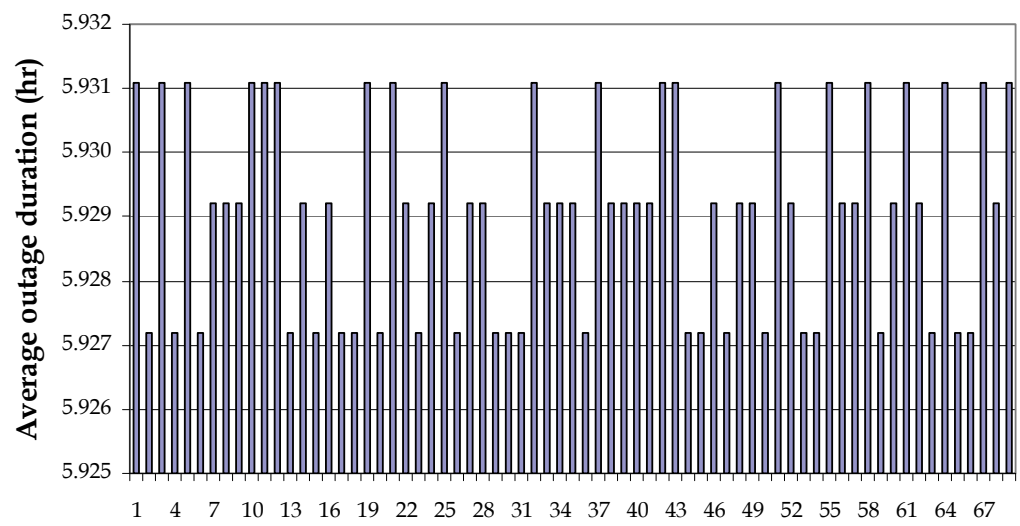

Load point

Fig. 8. Average outage duration of load points of 69-bus system

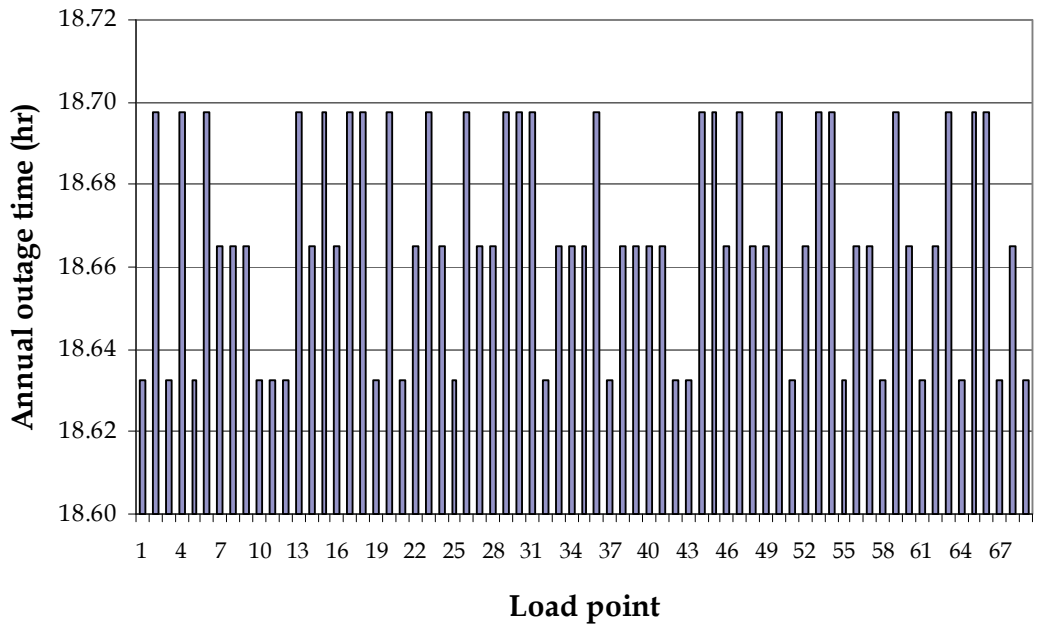

Fig. 9. Annual outage time of load points of 69-bus system

In fact, feeder reconfiguration attempts to balance the risk of losing customer load points with high interruption costs and those with low interruption costs so that the total customer interruption cost is minimized. With this logical idea, feeder reconfiguration can, therefore, result in overall reliability improvement. 


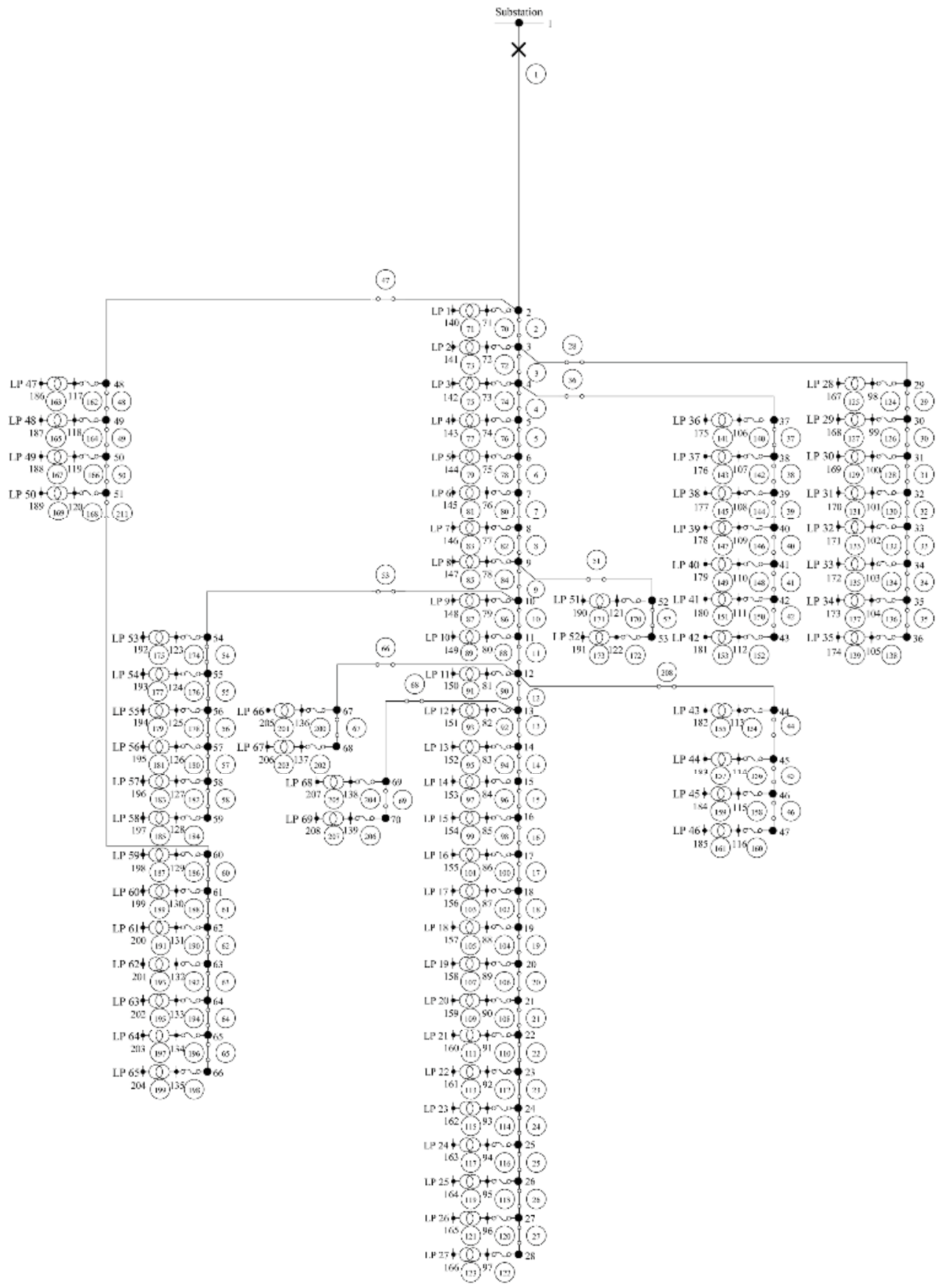

Fig. 10. 69-bus system after reconfiguration 


\begin{tabular}{|l|l|l|}
\hline & Before reconfiguration & After reconfiguration \\
\hline SAIFI (failure/customer/yr) & 3.1478 & 3.0568 \\
\hline SAIDI (hr/customer/yr) & 18.664 & 16.860 \\
\hline ASUI & 0.002131 & 0.001925 \\
\hline ASAI & 0.997869 & 0.998075 \\
\hline ENS (MWh/yr) & 0.982128 & 0.88387 \\
\hline AENS (MWh/customer/yr) & 0.160478 & 0.14442 \\
\hline ECOST (\$/yr) & 159,672 & 131,873 \\
\hline Sectionalizing switches to be open & - & 43,59 \\
\hline Tie switches to be closed & - & 208,211 \\
\hline
\end{tabular}

Table 8 . Simulation results before and after reconfiguration for 69-bus system

\section{Conclusion}

The network reconfiguration problem for reliability enhancement is solved by the developed simulated annealing in conjunction with reliability worth analysis that provides an indirect measure for cost implication associated with power failure. The objective is to minimize customer interruption cost with the constraints that all load points have to be electrically supplied and radially connected. It can be seen from the results of the RBTS and the 69-bus system that the total customer interruption cost can be reduced (i.e., the system reliability worth is enhanced) and system reliability indices are improved if the network is properly configured. Some other benefits that can be obtained from the network configuration could also be taken into account such as loss reduction and load balancing. In such case, a multi-objective optimization problem will result where achieving one objective usually comes at the expense of the others and therefore a priority ranking is generally required. Other constraints may be included such as the number of switching operations of sectionalizing and tie switches.

\section{References}

Brown, R. E. (2001). Distribution Reliability Assessment and Reconfiguration Optimization, IEEE Transmission and Distribution Conference and Exposition, Vol. 2, pp. 994-999, ISBN 0780372859, USA, October 2001, Atlanta.

Chowdhury, A. A. \& Koval, D. O. (2001). Application of Customer Interruption Costs in Transmission Network Reliability Planning, IEEE Transactions on Industry Application (November/December 2001), Vol. 37, No. 6, pp. 1590-1596.

Sarma, N. D. R. \& Prakasa Rao, K. S. (1995). A New 0-1 Integer Programming Method of Feeder Reconfiguration for Loss Minimization in Distribution Systems, Electric Power Systems Research, (May 1995), Vo. 33, No. 2, pp. 125-131.

Kashem, M. A.; Jlasmon G. B.; Mohamed A. \& Moghavvemi M. Artificial Neural Network Approach to Network Reconfiguration for Loss Minimization in Distribution Networks, Electrical Power and Energy Systems, (May 1998), Vol. 20, No. 4, pp. 247258.

Chang, H. \& Kuo, C. (1994). Network Reconfiguration in Distribution Systems Using Simulated Annealing, Electric Power Systems Research, (May 1994), Vo. 29, No. 3,pp. 227-238. 
Zhou, Q.; Shirmohammadi, D., \& Liu, E. (1997). Distribution Feeder Reconfiguration for Service Restoration and Load Balancing, IEEE Transactions on Power Systems, (May 1997), Vol. 12, No. 2, pp. 724-729.

Rugthaicharoencheep, N. \& Sirisumrannukul, S. (2009). Feeder Reconfiguration for Loss Reduction in Distribution System with Distributed Generators by Tabu Search. The Greater Mekong Subregion Academic and Research Network International Journal, (March 2009), Vol. 3, No. 2., pp. 47-54.

$\mathrm{Su}, \mathrm{C}$. \& Lee, C. (2001). Feeder Reconfiguration and Capacitor Setting for Loss Reduction of Distribution Systems, Electric Power Systems Research, (June 2001), Vol. 58, No. 2, pp. 97-102.

Tsai, L. (1993). Network Reconfiguration to Enhance Reliability of Electric Distribution Systems, Electric Power Systems Research, (July 1993), Vol. 27, No. 2, pp. 135-140.

Bin, Y.; Xiu-Li W.; Bie Zhao-Hong, B. \& Xi-Fan, W. (2002). Distribution Network Reconfiguration for Reliability Worth Enhancement, Proceedings of International Conference on Power System Technology, Vol. 4, pp. 2547-2550, ISBN 978-0-852-96748-5 , China, October 2002, Kunming.

Aarts, E. \& Korst, J. (1991). Simulated Annealing and Boltzmann Machines: A Stochastic Approach to Combinatorial Optimization and Neural Computing, Wiley Publishers, ISBN 978-0471-92146-2, United States of America.

Winton, W. \& Venkataramanan, M. A. (2003). Introduction to Mathematical Programming, Thomson, ISBN 978-0-534-35964-5, United States of America.

Weck, O. \& Jilla, C. (2004). Simulated Annealing a Basic Introduction, http://ocw.mit.edu/ NR/rdonlyres/ Aeronauticsand-Astronautics/16-888Spring-2004/5F6CFF91-524F4792-859D-98331A73AC7C/0/110a_sa.pdf

Billinton, R. \& Allan, R. N. (1996). Reliability Evaluation of Power Systems, Plenum Press, ISBN 978-0-306-45259-8, United States of America.

Geol, L.; Billinton, R. \& Gupta R. (1991). Basic Data and Evaluation of Distribution System Reliability Worth, Proceedings of IEEE Western Canada Conference on Computer, Power and Communications Systems in a Rural Environment, pp. 271-277, ISBN 0-87942-5946, Canada, May 1991, Regina.

Geol, L. \& Billinton, R. (1994). Determination of Reliability Worth for Distribution System Planning, IEEE Transactions on Power Delivery, (July 1994), Vol. 9, No. 3, pp. 1577-1583.

Allan, R. N.; Billinton, R.; Sjarief, I.; Goel, L. \& So, K. S. (1991). A Reliability Test System for Educational Purposes-Basic Distribution System Data and Results, IEEE Transactions on Power Systems, (May 1991), Vol. 6, No. 2, pp. 813-820.

Chiang H.D. \& Jean-Jameau R.M. (1990). Optimal Network Reconfigurations in Distribution Systems, Part 2. Solution Algorithms and Numerical Results, IEEE Transactions on Power Delivery, (July 1990) Vol. 5, No. 3, pp. 1568-1574.

\section{Acknowledgement}

The assistance from Mr. Sakulpong, A. and Mr. Rugthaicharoencheep, N. is sincerely acknowledged. 


\section{Appendix A}

A.1 Roy Billinton Test System (RBTS)

\begin{tabular}{|c|c|c|c|c|}
\hline Component & $\lambda$ & $r$ & $s$ & \\
\hline Transformer & 0.0150 & 200 & - & \\
\hline Line & 0.0650 & 5 & 1.0 & \\
\hline & $\lambda$ & \multicolumn{3}{|c|}{$\begin{array}{l}=\text { failure rate }(\mathrm{f} / \mathrm{km}-\mathrm{yr}) \\
=\begin{array}{l}\text { repair time and } \\
\text { replacement time }(\mathrm{hr})\end{array}\end{array}$} \\
\hline & $S$ & \multicolumn{3}{|c|}{$=$ switching time $(\mathrm{hr})$} \\
\hline
\end{tabular}

Table A.1. Component reliability data

\begin{tabular}{|c|c|l|}
\hline Feeder type & $\begin{array}{c}\text { Length } \\
(\mathbf{k m})\end{array}$ & \multicolumn{1}{|c|}{ Feeder section numbers } \\
\hline 1 & 0.60 & $4,7,8,14,26,32,33,43,47,49$ \\
\hline 2 & 0.75 & $1,2,3,6,18,24,27,30,31,35,39,45,55$ \\
\hline 3 & 0.80 & $10,12,16,20,22,23,25,29,37,41,51,53,57$ \\
\hline
\end{tabular}

Table A.2. Feeder data

\section{Tranformer section numbers}

$9,11,13,15,17,19,21,22,23,34,36$,

$38,40,42,44,46,48,50,52,54,56,58$

Table A.3. Tranformer data

\begin{tabular}{|l|l|l|l|l|l|}
\hline $\begin{array}{l}\text { Number of } \\
\text { load points }\end{array}$ & $\begin{array}{l}\text { Load points } \\
(\mathbf{L P})\end{array}$ & $\begin{array}{l}\text { Customer } \\
\text { type }\end{array}$ & $\begin{array}{l}\text { Average } \\
\text { load (MW) }\end{array}$ & $\begin{array}{l}\text { Peak } \\
\text { load (MW) }\end{array}$ & $\begin{array}{l}\text { Number of customers } \\
\text { per load point }\end{array}$ \\
\hline 5 & $1,2,3,10,11$ & Residential & 0.535 & 0.8668 & 210 \\
\hline 4 & $12,17,18,19$ & Residential & 0.450 & 0.7291 & 200 \\
\hline 1 & 8 & $\begin{array}{l}\text { Small } \\
\text { industrial }\end{array}$ & 1.00 & 1.6279 & 1 \\
\hline 1 & 9 & $\begin{array}{l}\text { Small } \\
\text { industrial }\end{array}$ & 1.15 & 1.8721 & 1 \\
\hline 6 & $4,5,13$, & Government & 0.566 & 0.9167 & 1 \\
\hline 5 & $14,20,21$ & Commercial & 0.454 & 0.7500 & 10 \\
\hline Total & $6,7,15,16,22$ & 12.291 & 20.00 & 1,908 \\
\hline
\end{tabular}

Table A.4. Customer and loading data

\section{A.2 69-Bus System}

\begin{tabular}{|c|c|c|c|c|}
\hline Component & $\lambda$ & $r$ & $S$ & \\
\hline Transformer & 0.0150 & 200 & - & \\
\hline Line & 0.0650 & 5 & 1.0 & \\
\hline & $\lambda$ & \multicolumn{3}{|c|}{$=\begin{array}{l}\text { repair time and } \\
\text { replacement time }(\mathrm{hr})\end{array}$} \\
\hline
\end{tabular}

Table A.5. Component reliability data 


\begin{tabular}{|l|l|}
\hline Length (km) & Feeder section numbers \\
\hline 0.60 & $3,5,6,7,9,14,16,17,19,21,23,24,27,28,33,35,37,41,45,46,48$, \\
& $51,55,57,60,62,63,66,67,70,74,78,88,90,92,106,110,118,132$, \\
& $142,152,154,170,178,184,190,196,202,206$ \\
\hline 0.70 & $2,4,12,13,18,20,26,30,31,32,36,38,43,47,54,59,64,65,68,82$, \\
& $84,86,96,100,112,116,122,124,134,136,138,144,146,148,150$, \\
& $160,164,166,172,180,182,188,192,204$ \\
\hline 0.80 & $1,8,10,11,15,22,25,29,34,39,40,42,44,49,50,52,53,56,58,61$, \\
& $69,72,76,80,94,98,102,104,108,114,120,126,128,130,140,156$, \\
& $158,162,168,174,176,186,194,198,200$ \\
\hline
\end{tabular}

Table A.6. Feeder data

\begin{tabular}{|l|}
\hline Tranformer section numbers \\
\hline $71,73,75,77,79,81,83,85,87,89,91,93,95,97,99,101$, \\
$103,105,107,109,111,113,115,117,119,121,123,125$, \\
$127,129,131,133,135,137,139,141,143,145,147,149$, \\
$151,153,155,157,159,161,163,165,167,169,171,173$, \\
$175,177,179,181,183,185,187,189,191,193,195,197$, \\
$199,201,203,205,207,208,209,210,211,212$ \\
\hline
\end{tabular}

Table A.7. Transformer data

\begin{tabular}{|l|l|l|l|l|l|}
\hline $\begin{array}{l}\text { Number of } \\
\text { load points }\end{array}$ & $\begin{array}{l}\text { Load points } \\
\text { LP) }\end{array}$ & $\begin{array}{l}\text { Customer } \\
\text { type }\end{array}$ & $\begin{array}{l}\text { Average } \\
\text { load (MW) }\end{array}$ & $\begin{array}{l}\text { Peak } \\
\text { load (MW) }\end{array}$ & $\begin{array}{l}\text { Number of customers } \\
\text { per load point }\end{array}$ \\
\hline 12 & $\begin{array}{l}1,2,13,14,25, \\
26,37,38,49, \\
50,60,61\end{array}$ & Commercial & 0.574 & 0.950 & 200 \\
\hline 11 & $\begin{array}{l}3,4,15,16,27, \\
28,39,40,51, \\
52,62\end{array}$ & Educational & 0.632 & 0.825 & 1 \\
\hline 10 & $\begin{array}{l}5,6,17,18,29, \\
30,41,42,53, \\
54\end{array}$ & $\begin{array}{l}\text { Office and } \\
\text { building }\end{array}$ & 0.988 & 1.412 & 10 \\
\hline \multirow{2}{*}{$\begin{array}{l}7,8,19,20, \\
31,32,43,44, \\
55,56,63,64, \\
65,66,67,68, \\
69\end{array}$} & $\begin{array}{l}\text { Residential } \\
9,10,21,22,\end{array}$ & 1.200 & 1.934 & 210 \\
\hline 10 & $\begin{array}{l}33,34,45,46, \\
57,58\end{array}$ & $\begin{array}{l}\text { Small } \\
\text { industrial }\end{array}$ & 0.555 & 0.878 & 3 \\
\hline 9 & $\begin{array}{l}11,12,23,24, \\
35,36,47,48, \\
59\end{array}$ & $\begin{array}{l}\text { Large } \\
\text { industrial }\end{array}$ & 0.327 & 0.798 & 1 \\
\hline Total & & 52.613 & 83.435 & 6,120 \\
\hline
\end{tabular}

Table A.8. Customer and loading data 
Simulated Annealing.

Theory with Applications

estes by hui chibants

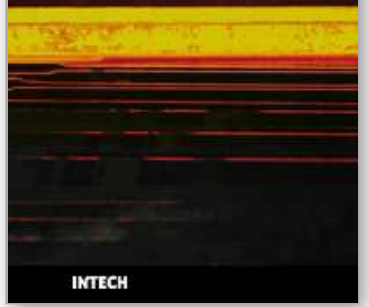

\section{Simulated Annealing, Theory with Applications}

Edited by Rui Chibante

ISBN 978-953-307-134-3

Hard cover, 292 pages

Publisher Sciyo

Published online 18, August, 2010

Published in print edition August, 2010

The book contains 15 chapters presenting recent contributions of top researchers working with Simulated Annealing (SA). Although it represents a small sample of the research activity on SA, the book will certainly serve as a valuable tool for researchers interested in getting involved in this multidisciplinary field. In fact, one of the salient features is that the book is highly multidisciplinary in terms of application areas since it assembles experts from the fields of Biology, Telecommunications, Geology, Electronics and Medicine.

\section{How to reference}

In order to correctly reference this scholarly work, feel free to copy and paste the following:

Somporn Sirisumrannukul (2010). Network Reconfiguration for Reliability Worth Enhancement in Distribution Systems by Simulated Annealing, Simulated Annealing, Theory with Applications, Rui Chibante (Ed.), ISBN: 978-953-307-134-3, InTech, Available from: http://www.intechopen.com/books/simulated-annealing--theorywith-applications/network-reconfiguration-for-reliability-worth-enhancement-in-distribution-systems-bysimulated-annea

\section{INTECH}

open science | open minds

\section{InTech Europe}

University Campus STeP Ri

Slavka Krautzeka 83/A

51000 Rijeka, Croatia

Phone: +385 (51) 770447

Fax: +385 (51) 686166

www.intechopen.com

\section{InTech China}

Unit 405, Office Block, Hotel Equatorial Shanghai

No.65, Yan An Road (West), Shanghai, 200040, China

中国上海市延安西路65号上海国际贵都大饭店办公楼 405 单元

Phone: +86-21-62489820

Fax: $+86-21-62489821$ 
(C) 2010 The Author(s). Licensee IntechOpen. This chapter is distributed under the terms of the Creative Commons Attribution-NonCommercialShareAlike-3.0 License, which permits use, distribution and reproduction for non-commercial purposes, provided the original is properly cited and derivative works building on this content are distributed under the same license. 